\title{
Reliability Evaluation of Kumpai Feeder Distribution System at PT. PLN (Persero) ULP Siantan
}

\author{
Ari Kurniawan ${ }^{1 *}$, Fitriah $^{2)}$, and M. Iqbal Arsyad ${ }^{3)}$ \\ 1,2,3) Department of Electrical Engineering, Universitas Tanjungpura, Indonesia \\ Corresponding Email: *) Arikurniawan1980@ student.untan.ac.id
}

\begin{abstract}
The research on reliability index of a feeder aims to evaluate the reliability level of a feeder using the Reliability Index Assessment (RIA) method. This method evaluates the reliability of a $20 \mathrm{kV}$ distribution network by calculating the reliability indexes of each load point. The evaluation results show the reliability index value per section of the Kumpai Feeder at PT. PLN (Persero) ULP Siantan within one year. The SAIFI values are $0.0092 ; 0.0012$; 12,$477 ; 0.0596 ; 0.0204 ; 0.0470 ; 0.0155 ; 0.0728$, the SAIDI values are $0.0277 ; 0.0042 ; 37,746 ; 0.1862 ; 0.0741 ; 0.1524$; $0.0493 ; 0.2209$, the CAIDI values are $3.0108 ; 3.5 ; 3,025$; $3.1241 ; 3.6323 ; 3.2425 ; 3.1806 ; 3.0343$, the MAIFI values are $0 ; 5,480 ; 0.2145 ; 0.0020 ; 0.0038 ; 0.0042 ; 0.0006 ; 0.0014$. The calculation results show that the $20 \mathrm{kV}$ distribution system at PT. PLN (Persero) ULP Siantan at the Kumpai Feeder can be categorized as unreliable. Because the SAIFI value of this feeder exceeds the standard set by PT. PLN (Persero) which are 12.477 times/customer/year and 3.2 times/customer/year, respectively. The factors affecting the reliability index of the Kumpai feeder are the number and duration of blackouts, the number of customers, and the length of the distribution system channel.
\end{abstract}

Keywords: Reliability Index, Kumpai Feeder, Load Point

\section{INTRODUCTION}

In an electric power distribution system, the level of reliability is very important in determining the performance of the system. This reliability can be seen from the extent to which the electricity can be supplied continuously in one year to consumers. The most basic problems in power distribution lies in quality, continuity, and availability of electric power services to customers. The people's standard of living is increasing year by year, followed by an increase in the demand for electricity. At this time electric power has become a primary necessity, so the continuity of electricity supply become a greater demand from consumers [1].

To increase the reliability of a distribution system, it is necessary to study the level of reliability of the electric power system. In this study, RIA method is used as it considers the failure rate to obtain the electricity, so that the results are closer to the actual result. Indexes used to assess the level of reliability of a distribution system are System Average Interruption Frequency Index (SAIFI), System Average Interruption Duration Index (SAIDI), Customer Average Interruption Duration Index (CAIDI), and Momentary Average Interruption Frequency Index (MAIFI) [1].
PT. PLN (Persero) ULP Siantan has 23 feeders where the working units are supplied by 3 substations (GI), 11 feeders are supplied by GI Siantan, 4 feeders are supplied by GI Parit Baru, and 8 feeders are supplied by GI Sei Raya. In the electricity distribution, there are many disturbances that occur at PT. PLN (Persero) ULP Siantan including external disturbances such as the network being hit by tree branches, kite strings, lightning strikes, disturbances due to animals and many others. To overcome this, it is necessary to evaluate the system to see how reliable the distribution network system is. Evaluation of the system reliability needs to be done by calculating the frequency of the average failure rate $(\lambda)$, the average interruption time (r), the annual average blackout time (U). Therefore, PLN is trying to meet the increasing demand for power and also improve the service quality so that the continuity of the supply of electric power can be maintained.

The reliability index of electrical distribution equipment depends on the frequency of blackouts (SAIFI) that occur every year, the duration of blackouts (SAIDI, CAIDI and MAIFI) informs about the average blackout frequency for each consumer within a year.

Analysis of feeder disturbance at PT. PLN (Persero) of West Java and Banten in Garut Rayon in 2012 showed that $36 \%$ outages caused by kites, and increased to $52 \%$ in 2013 [1]. Evaluation of the reliability of the distribution network system using SAIDI and SAIFI indexes at PT. PLN (Persero) Pontianak area, the main channel of the primary distribution network for the $20 \mathrm{kV}$ feeder, the calculation includes all the main components in it [2], Analysis of the Reliability of the $20 \mathrm{kV}$ Distribution System on the Pejangkung Feeder at PT PLN Pasuruan Using the RIA method to determine the reliability value and various indices related to quality of service to customers [3], Evaluation of the Reliability of the Electric Power Distribution System in the Fertilizer Industry calculates the reliability index of SAIFI, MAIFI, SAIDI and CAIDI based on the failure rate and repair time as well as the number of components at each loading point [4]. Reliability Analysis of Distribution Network Based on Reliability Index Assessment Method, A Case Study From the simulation point of view, the system average interruption frequency index (SAIFI) is about $19.43 \%$ or decreased the failure frequent event from 11.4 failure/ customer/year to 9.25 failure/customer/year; while the momentary average interruption frequency index 
(MAIFI) has decreased from 6.72 failure/customer/year to 5.05 failure/customer/year, or increase the reliability index of about $24.85 \%$ [5].

In this study, the authors determine the value of reliability and various indexes related to the quality of service to customers. Therefore, this study aims to determine the reliability of the $20 \mathrm{kV}$ distribution network power system at the Kumpai Feeder. It is carried out by seeing how much and how big the disturbance affects the distribution of electricity to consumers as well as reevaluating the reliability index of the $20 \mathrm{kV}$ distribution system electric power using RIA method.

\section{MeTHODOLOGY}

\section{A. Basic Theory of Distribution System Reliability}

Reliability of the distribution system indicates the probability of the distribution system to be able to perform its functions properly within a certain period of time, and under certain working conditions. The reliability level of the distribution system is measured by the extent to which electricity distribution can take place continuously to customers without power outage incidents [4].

Every year the demand in electricity services is increasing, not only the increase in power supply, but the reliability of the system also needs to be considered. Most problems regarding the reliability of the distributor of the electrical system come from the distribution system. Therefore, special attention is needed if the reliability of the distribution system is to be increased [1].

There are several important terms related to the reliability of distribution systems including:

1. Outage is reliability where a component cannot perform its function due to factors that are directly related to the component. An outage may or may not result in an outage depending on the system configuration;

2. Forced outage is an outage caused by an emergency that is directly related to a component, where it is necessary for the component to be removed from the system immediately. Outage can be caused by errors in equipment operation or human error;

3. Scheduled outage is an outage that occurs when a component is intentionally removed from the system at predetermined times, usually for the purpose of periodic repair or maintenance;

4. Interruption is termination of work (blackout) at one or more consumers or facilities as a result of an outage that occurs in one or more components;

5. Forced interruption is a blackout caused by a forced outage. Scheduled interruption is a blackout caused by a scheduled outage;

6. Failure rate $(\lambda)$ is the average number of failures that occur in a component within a certain time, generally time is expressed in years and failure rate is expressed in failure/year;

7. Outage time (r) is the time used to repair or replace parts of the equipment due to failure or the period from the start of the equipment failure to the time the equipment returns to normal (general outage time is expressed in hours/failure).
Reliability is the possibility of continuous load service with decent electrical service quality for a certain period with suitable operating conditions and one of the important requirements in the electric power system. The reliability of the electric power system is very dependent on the reliability of the system support equipment, the natural process of the equipment and the errors in operating the equipment. The selection of the failure criteria is very dependent on the type of load at the point of attention, which is suitable with the maximum time of blackout that does not interfere with the work of the load. The reliability index of a distribution system is used to measure the level of reliability of each load point. The basic reliability indexes include $\lambda$ as the average annual failure frequency (failures/year), $r$ as the average length of power outage (hours/failure), and $U$ as the duration of the average annual electricity supply cut (hours/year).

The basic reliability index above shows that both reliability and the failure value are a function of time. Changes in the value of the failure rate with respect to operating time is related to initial, normal, and final operation failure as shown in Figure 1 [1], [4]-[6].

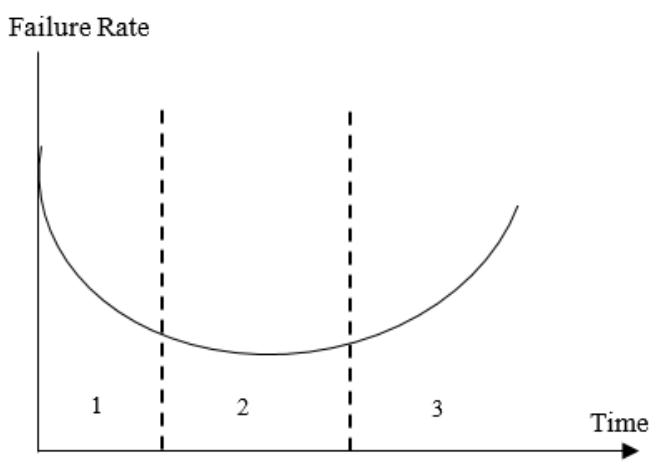

Figure 1. Failure Rate Against Time

In Figure 1 it can be seen that area one is the initial failure area where the failure value of a component at the start of operation is relatively high and the value will decrease with operating time. In the initial period of operation of a new component or system, its reliability is still $100 \%$ within a short period of time. Damage that occurs is generally caused by defect in manufacturing or fabrication. Area two is normal failure after going through the initial failure area, the component can be operated normally with a relatively constant failure value. In this period, most of the service life of the component or system is in the constant failure rate with time. Area number three is the final failure, where all components have passed their economic elements, so they are no longer operated according to their functions. This period ends when the reliability of this component or system approaches zero, so that the damage occurred is very severe and cannot be repaired [4],[7],[8].

The three things above show that these events succeeded or failed, and of course it is highly suggested to formulate problems related to several operating conditions, including maintenance, normal, standby, critical and very serious conditions. Failure rate is the average value of the number of errors per time unit at a 
certain time interval of observation (T), and is expressed as failure per year. The failure rate value is expressed as follows:

$$
\lambda=\frac{d}{t}
$$

where:

$$
\begin{aligned}
& \lambda=\text { failure rate (failures/year) } \\
& \mathrm{d}=\text { number of failures that occur at time } \mathrm{T} \\
& \mathrm{T}=\text { observation time interval (years) }
\end{aligned}
$$

The failure rate will change according to the age of the system or electrical equipment during operation.

1. Annual average failure rate

$$
\lambda_{l p}=\sum_{i=k} \lambda_{i}
$$

where:

$\lambda_{l p}=$ Equipment failure rate $\times$ length of air duct.

2. Average annual duration of interruption

where:

$$
U_{l p}=\sum_{j-1} U_{i}=\sum_{j-1} \lambda_{i} x r_{j}
$$

$U_{l p}=$ Average annual interruption (hours/year)

$r_{j}=$ Repair time/switching time/reclosing time

3. Mean Time To Failure (MTTF)

MTTF is the time a system takes to be able to work from the time the failure starts to the time it returns to normal. The equation is:

$$
\mathrm{MTTF}=\frac{1}{\lambda}
$$

If more than 1 component is involved, then the average time to failure is:

$$
M T T F=\bar{m}=\frac{\Sigma_{i=1}^{g} m i}{g}
$$

where:

$$
\begin{aligned}
& \bar{m}=\text { average time to failure } \\
& m_{i}=\text { average feeder failure time } \\
& \mathrm{g}=\text { number of failures }
\end{aligned}
$$

4. Mean Time To Repair (MTTR)

MTTR is the time a system takes to recover; in this case the repair time is the time interval from the start of failure to the time the function returns to normal. The equation is:

$$
\mathrm{MTTR}=r=\frac{1}{\mu}
$$

If more than 1 component is involved, then the average time to recover is:

$$
\mathrm{MTTR}=\bar{r}=\frac{\sum_{i=1}^{g} r i}{g}
$$

where:

$$
\begin{aligned}
& \bar{r}=\text { average time to recover } \\
& r_{i}=\text { average feeder repair time } \\
& \mathrm{g}=\text { number of failures }
\end{aligned}
$$

5. Mean Time Between Failure (MTBF)

MTBF is the average time elapsed between a repairable failure and the next time it occurs. It represents the availability and reliability the system, so the higher the value of MTBF, the more reliable the system is. Meanwhile MTTR is an indicator of the ability of machine maintenance operators in handling or overcoming problems.

$$
\mathrm{MTBF}=\bar{T}=M T T F+M T T R=\bar{m}+\bar{r}
$$

where:

$\bar{T}=$ average time between failures

6. Average System Availability Index (ASAI)

$$
\mathrm{A}=\frac{M T T F}{M T B F+M T T R}
$$

7. Average System Unavailability Index (ASUI)

$$
(\bar{A})=\frac{M T T R}{M T T F+M T T R}
$$

- SAIFI

$$
\text { SAIFI }=\frac{\Sigma N_{i . \lambda_{i}}}{\Sigma N}
$$

where:

$N_{i}=$ number of consumers at load point

$\lambda_{i}=$ failure rate at load point

- SAIDI

$N=$ number of consumers of the feeder

where:

$$
\text { SAIDI }=\frac{\Sigma N_{i} \cdot U_{i}}{\Sigma N}
$$

$U_{i}=$ average interruption time of feeder load point

$N_{i}=$ number of customers on feeder load point

$N=$ total number of customers

- CAIDI

$$
C A I D I=\frac{S A I D I}{S A I F I}=\frac{\Sigma U_{i} \cdot N_{i}}{\Sigma \lambda_{i} \cdot N_{i}}
$$

where:

$U_{i}=$ average interruption time of load point feeder

$\lambda_{i}=$ failure rate of feeder load point

$\mathrm{N}=$ number of customers of the feeder

- MAIFI

$$
M A I F I=\sum_{i=1}^{m} \frac{\lambda_{m} \cdot T_{i}}{n}
$$

where:

$\lambda_{m}=$ momentary failure rate of components $<5$ minutes (failure/year)

$T_{i}=$ number of customers experiencing momentary interruption due to component failure $\mathrm{i}$

$n=$ number of customers on the system

$m=$ number of components

Table 1. Standard Reliability Index

\begin{tabular}{c|c|c}
\hline $\begin{array}{c}\text { Working } \\
\text { Indicator }\end{array}$ & $\begin{array}{c}\text { Standard } \\
\text { Value }\end{array}$ & Unit \\
\hline SAIFI & 3.2 & times/customer/year \\
\hline SAIDI & 21.09 & hours/customer/year \\
\hline
\end{tabular}

Source: SPLN No 68-2: 1986

Table 2. Standard Equipment Failure Index

\begin{tabular}{cccc}
\hline Component & $\begin{array}{c}\text { Failure Rate } \\
\lambda\end{array}$ & $\begin{array}{c}\text { Repair } \\
\text { Time } \\
\text { (hour) }\end{array}$ & $\begin{array}{c}\text { Switching } \\
\text { Time } \\
\boldsymbol{r} \text { (hour) }\end{array}$ \\
\hline $\begin{array}{c}\text { Transformator } \\
\text { Distribution }\end{array}$ & $0.005 /$ unit/year & 10 & 0.15 \\
\hline CB & $0.004 /$ unit/year & 10 & 0.15 \\
\hline Recloser & $0.003 /$ unit/year & 10 & 0.15 \\
\hline LBS & $0.004 /$ unit/year & 10 & 0.15 \\
\hline
\end{tabular}

Source: SPLN 59, 1985

Table 3. Standard Reliability Index

\begin{tabular}{c|c}
\hline \multicolumn{2}{c}{ Air duct } \\
\hline Sustained failure rate $(\lambda / \mathrm{km} /$ year) & 0.2 \\
\hline Repair time, R (hours) & 3 \\
\hline Switch time, Rs (hours) & 0.15 \\
\hline
\end{tabular}

Source: SPLN 59, 1985 


\section{B. Research Method}

The research was conducted at PT. PLN (Persero) ULP Siantan with Kumpai Feeder as the study object. The data obtained are: single line diagram of feeder meet, interruption (duration and number of interruptions), channel length, the number of customers, uptime, and service recovery.

The research methods carried out in this study are as follows:

1. Literature study includes studying reference books, manuals, articles, and internet for supporting materials related to the topic of this research.

2. Field observations, which involves visiting the sites to obtain information related to Kumpai Feeder.

3. Quantitative methods, i.e., the calculation and use of numbers. In addition, this study also calculates the failure value, the duration of the disturbance $U$ per load point, system failures per section MTTF, MTTR, MTBF, ASAI and ASUI, and also the reliability indexes of SAIFI, SAIDI, CAIDI, and MAIFI, and then compares them with the standard of SPLN 68-2: 1986.

In this research, the aimed results are the basic condition index and the reliability index of the Kumpai feeder system. The steps to obtain those indexes are as follows:

1. One of the variables that must be calculated first is the annual reliability index of the feeder, the reliability index value is obtained by using network disturbance data of the feeder in 2019, from the start to the end of power outage. The calculated reliability indexes are the average rate value, failure rate, the average repair rate, and the annual repair rate.

2. Perform load point reliability calculations using the RIA method.

3. Identify a single line diagram, which is the first step to find the reliability value of the load point using the RIA method.

4. Determine the system reliability index, i.e., SAIFI, SAIDI, CAIDI, and MAIFI. The data required for this calculation are $\lambda_{\mathrm{lp}}$ (load point failure rate), $\mathrm{U}_{\mathrm{lp}}$ (annual unavailability average load point), and $r_{l p}$ (average load point outage), as well as data on the number of customers per load point.

5. After obtaining the calculation results of SAIDI, SAIFI, and CAIDI then the results are compared to SPLN 68: 1986 regarding the standard value where for SAIFI is 3.2 times/year and SAIDI is 21.09 hours/year.

The stages carried out in this study can be seen in Figure 3.

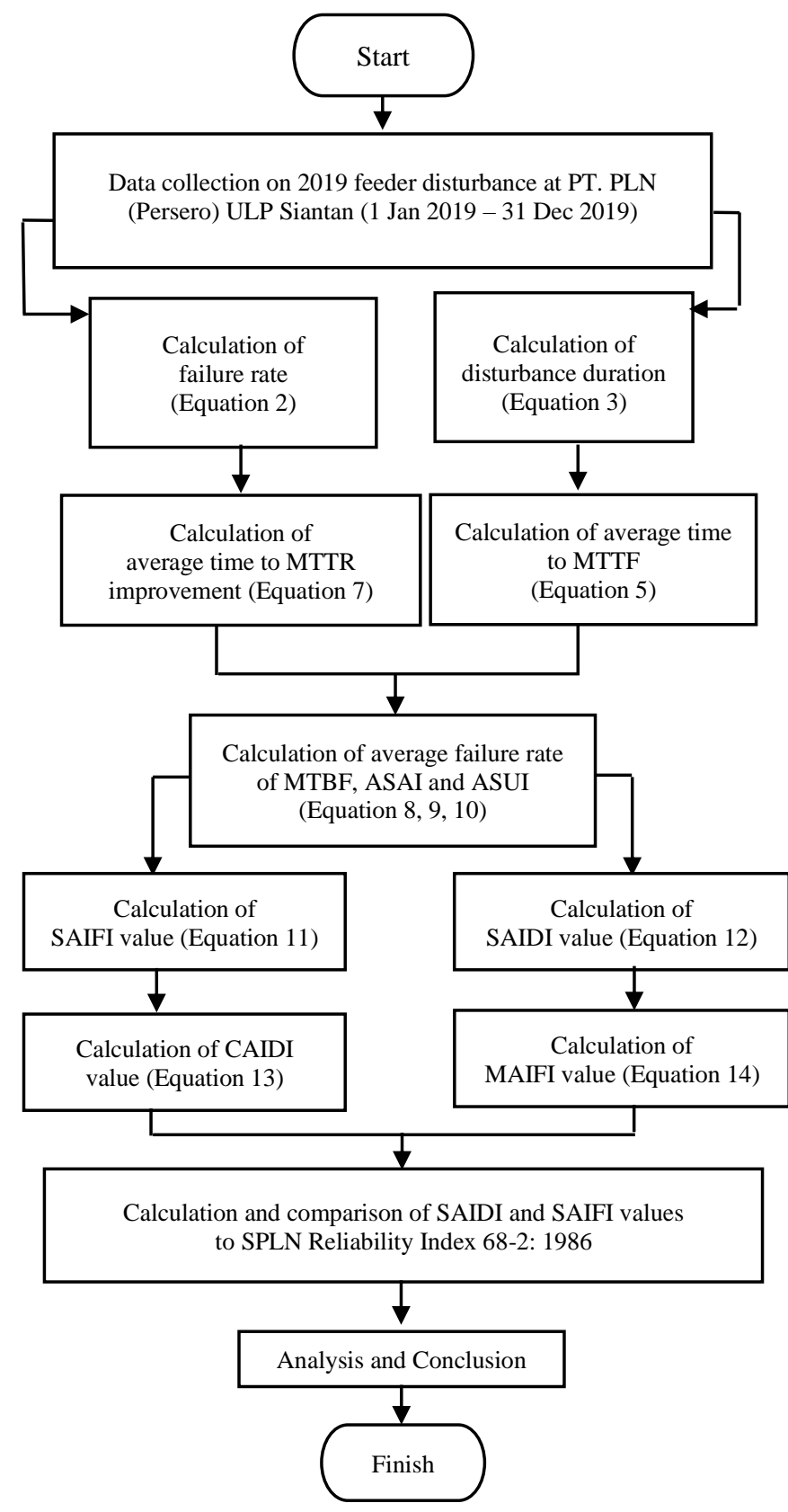

Figure 2. Research Flowchart

\section{RESUlts AND DiscuSSION}

\section{A. Calculation Results}

The Kumpai feeder is supplied by the Sei Raya Substation with a power of 60 MVA. This feeder has a load variation at the load point in the form of industrial and household loads. This feeder has 151 load points in the form of distribution transformers with a total of 15,253 subscribers and a network length of $127.87 \mathrm{Kms}$. The feeder is divided into 8 sections. The number of customers charged at the load points of this feeder is shown in Table 5. 
Table 5. Number of Customers in Each Section and Load Point

\begin{tabular}{crrrr}
\hline Section & $\begin{array}{c}\text { Load } \\
\text { Point }\end{array}$ & $\begin{array}{c}\text { Capacity } \\
(\mathbf{k V A})\end{array}$ & $\begin{array}{c}\text { Number of } \\
\text { Customers } \\
\left(\mathbf{N}_{\mathbf{i}}\right)\end{array}$ & $\begin{array}{c}\text { Length } \\
(\mathbf{K m s})\end{array}$ \\
\hline 1 & 1 & 160 & 172 & 4.106 \\
\hline 2 & 1 & 200 & 209 & 0.452 \\
\hline 3 & 89 & 12.055 & 11.949 & 80.2434 \\
\hline 4 & 11 & 1.355 & 598 & 7.9117 \\
\hline 5 & 11 & 575 & 569 & 3.2646 \\
\hline 6 & 16 & 1.710 & 649 & 6.515 \\
\hline 7 & 7 & 275 & 297 & 4.165 \\
\hline 8 & 15 & 750 & 810 & 6.993 \\
\hline Total & 151 & 17.080 & 15.253 & 113.6507 \\
\hline & & & & \\
\hline
\end{tabular}

The formula of system failure values and $U$ per load point are as follows:

1. $\lambda_{l p}=$ Equipment failure rate $\times$ length of air duct $(\mathrm{kms})$. Failure rate $=0.2$ (Table 3$)$

2. $U_{l p}=\sum_{j-1} U_{i}=\lambda_{l p} x r_{j}$

$r_{\text {line }}=3$ hours

$r_{L B S}=10$ hours

Table 6. Calculation Result of System Failure of Kumpai Feeder per Section

\begin{tabular}{crrrr}
\hline Section & \multicolumn{1}{c}{$\boldsymbol{\lambda}_{\boldsymbol{l} \boldsymbol{p}}$} & \multicolumn{1}{c}{$\boldsymbol{\lambda}_{\mathbf{s}}$} & \multicolumn{1}{c}{$\boldsymbol{\lambda}_{\mathbf{m}}$} & \multicolumn{1}{c}{$\mathbf{U}_{\mathbf{i}}$} \\
\hline 1 & 0.821 & 0.821 & - & 2.463 \\
\hline 2 & 0.094 & 0.094 & 0.004 & 0.31 \\
\hline 3 & 16.05208 & 15.92722 & 0.29082 & 48.18424 \\
\hline 4 & 1.574 & 1.522 & 0.052 & 4.75 \\
\hline 5 & 0.653 & 0.549 & 0.104 & 1.987 \\
\hline 6 & 1.205 & 1.106 & 0.099 & 3.5836 \\
\hline 7 & 0.835 & 0.8 & 0.035 & 2.533 \\
\hline 8 & 1.398 & 1.371 & 0.027 & 4.1599 \\
\hline Total & 22.63208 & 22.19022 & 0.61182 & 67.97074 \\
\hline
\end{tabular}

where:

$\lambda_{l p}=$ failure rate (failures/year)

$\lambda_{s}=$ failure rate that is $>5$ minutes load point

$\lambda_{m}=$ momentary failure rate of components $<5$ minutes (failure/year)

$\mathrm{U}_{\mathrm{i}}=$ Average annual interruption (hours/year)

$N_{i}=$ number of consumers at load point (load point)

Table 7. Calculation of System Failure, Availability, and Unavailability

\begin{tabular}{rrrrrrr}
\hline No & $\begin{array}{c}\text { MTTF } \\
\text { (hour) }\end{array}$ & $\begin{array}{c}\text { MTTR } \\
\text { (hour) }\end{array}$ & $\begin{array}{c}\text { MTBF } \\
\text { (hour) }\end{array}$ & ASAI & ASUI \\
\hline 1 & 10,666 & 3 & 10.669 & 0.9997 & 0.000281 \\
\hline 2 & 93,188 & 3,297 & 93.191 & 0.9999 & 3.537895 \\
\hline 3 & 530,613 & 2,963 & 533.576 & 0.9944 & 0.005553 \\
\hline 4 & 5,562 & 3,017 & 5,565 & 0.9994 & 0.000542 \\
\hline 5 & 13,411 & 3,042 & 13,414 & 0.9997 & 0.000226 \\
\hline 6 & 7,266 & 2,973 & 7,268 & 0.9997 & 0.000409 \\
\hline 7 & 10,487 & 3,033 & 10,490 & 0.9997 & 0.000289 \\
\hline 8 & 6,263 & 2,975 & 6,265 & 0.9996 & 0.000474 \\
\hline
\end{tabular}

In Table 7, it can be seen that the largest MTTF and MTBF values in section three are 530,613 hours and 533,576 hours, respectively. These numbers indicate that this section encountered many disturbances as it has the largest number of customers. The MTTR in section two has the greatest value, i.e., 3,297 hours, because the disturbances in that section are slower to overcome. While section three is the one with the shortest average time to repair, i.e., 2,963 hours, because when a disturbance occurs, it is quickly resolved. From Table 7, it can be seen that the ASAI (system availability) is higher than the ASUI (system unavailability) value. This shows the performance of PT. PLN (Persero) ULP Siantan.

Table 8. SAIFI, SAIDI, CAIDI, and MAIFI Reliability Indexes of Kumpai Feeder

\begin{tabular}{crrrr}
\hline Section & \multicolumn{1}{c}{ SAIFI } & \multicolumn{1}{c}{ SAIDI } & \multicolumn{1}{c}{ CAIDI } & \multicolumn{1}{l}{ MAIFI } \\
\hline 1 & 0.0092 & 0.0277 & 3.0108 & 0 \\
\hline 2 & 0.0012 & 0.0042 & 3.5 & 5.480 \\
\hline 3 & 12.477 & 37.746 & 3.025 & 0.2145 \\
\hline 4 & 0.0596 & 0.1862 & 3.1241 & 0.0020 \\
\hline 5 & 0.0204 & 0.0741 & 3.6323 & 0.0038 \\
\hline 6 & 0.0470 & 0.1524 & 3.2425 & 0.0042 \\
\hline 7 & 0.0155 & 0.0493 & 3.1806 & 0.0006 \\
\hline 8 & 0.0728 & 0.2209 & 3.0343 & 0.0014 \\
\hline Total & 12.7027 & 38.8308 & 25.7786 & 5.7065 \\
\hline
\end{tabular}

Table 8 shows that the MAIFI value in section one is zero, implying that there is no temporary disturbance or the one with a duration of less than five minutes. In section three, it can be seen that the SAIFI and SAIDI values are the highest among all sections, indicating that there are more outage incidents in this section compared to the others.

\section{B. Comparison of SAIFI Values}

The SAIFI value as the target of PLN as in SPLN 68 2: 1986 is 3.2 times/customer/year. The SAIFI values of each section can be seen in Table 8 .

\section{Comparison of SAIFI Value with PLN SPLN Target 68 - 2: 1986}

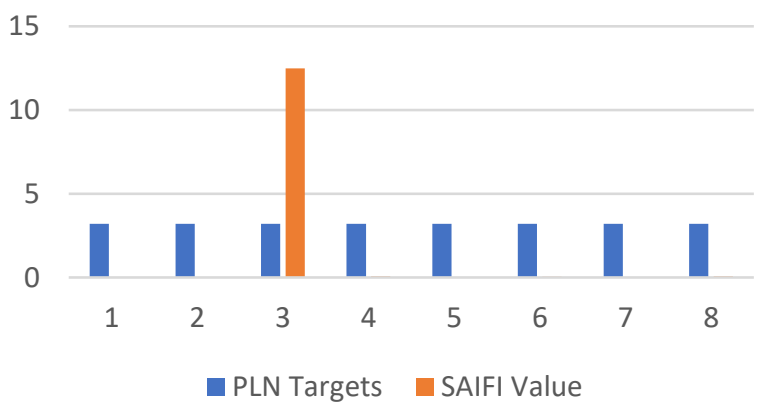

Figure 3. SAIFI Values of Each Section

From the calculation results, the highest SAIFI value is shown in section three, i.e., 12.477 times/customer/year and when compared to the one in SPLN 68-2: 1986 which is 3.2 times/customer/year, it can be concluded that the SAIFI reliability index of Kumpai Feeder is considered low and unreliable as it exceeds the SPLN standard.

\section{Comparison of SAIDI Values}

The SAIDI standard value as in SPLN 68-2: 1986 is 21.09 hours/customer/year. Table 8 summarizes the SAIDI values of each section. 


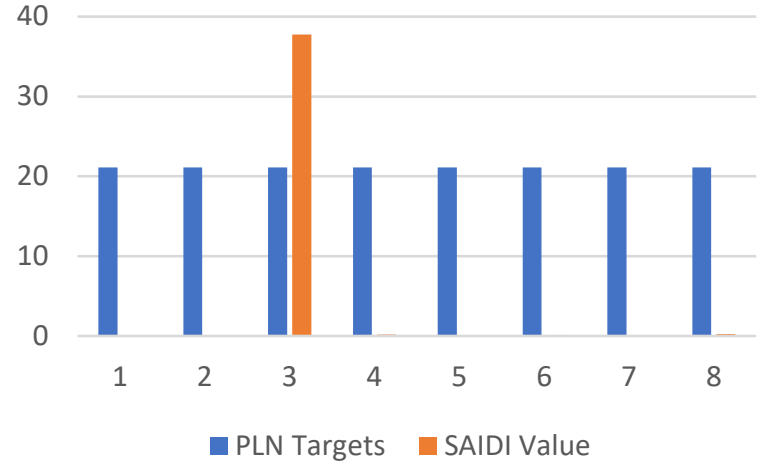

Figure 4. SAIDI Values of Each Section

From the calculation results, section three has the highest SAIDI value of 37.746 hours/customer/year and the standard of SPLN 68-2: 1986 which is 21.09 hours/customer/year. It can be concluded that the SAIDI reliability index of Kumpai feeder is poor and unreliable as it has a higher value compared to the PLN target as in SPLN 68-2: 1986.

\section{Comparison of CAIDI Values}

The CAIDI values of each section can be seen in Table 8.

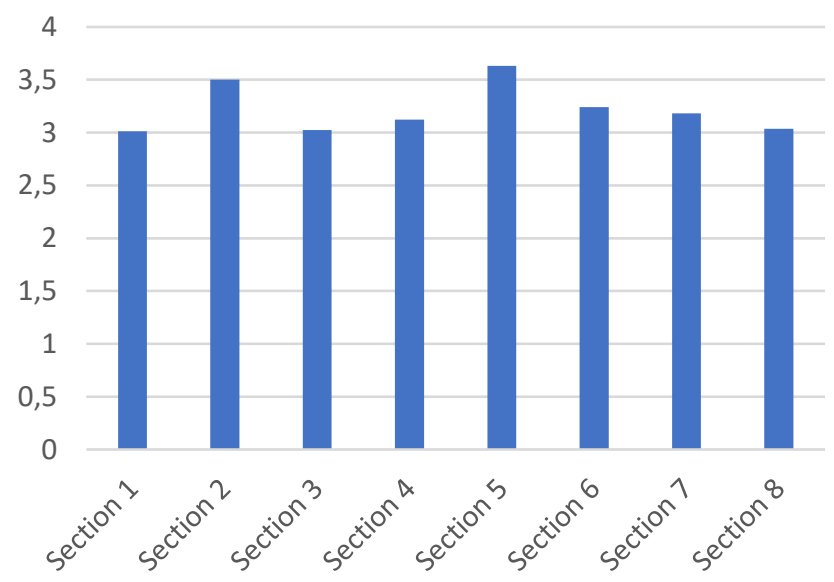

Figure 5. CAIDI Values of Each Section

Figure 5 shows that the highest CAIDI value, which indicates the average duration of interruption for each customer, is in section five, i.e., 3.6323 hours/customer/ year, this indicates that the duration of continuous interruption (power outage) in section five is the most important as it is higher than the other sections. While the lowest CAIDI value is in section seven, i.e., 0.59961 hours/customer/year, showing that the section has the least disturbance (outage) followed by section eight, section three, section six, section four, section one, and section two. The calculation results imply that the CAIDI values are relatively high. So, it can be concluded that the duration of interruptions occuring in Kumpai Feeder is still high, hence, further improvement is required.

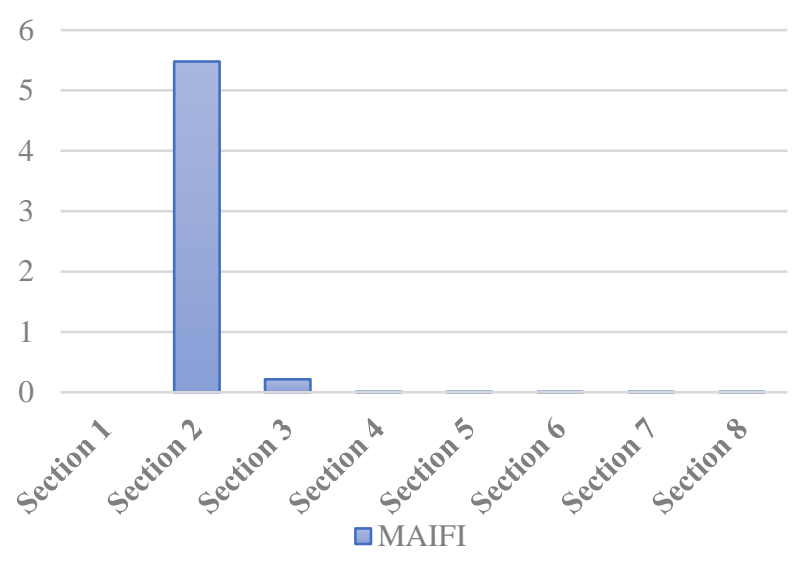

Figure 6. MAIFI Values of Each Section

\section{E. Comparison of MAIFI Values}

The MAIFI values of each section are shown in Table 8. the highest MAIFI value or the average number of temporary disturbances per customer throughout the year is found in section two which is 5,480 times/customer/ year, this indicates that the disturbance in section two is the worst compared to the other sections. While the lowest MAIFI value is found in section one, which is 0 times/ customer/year, which means that in that section there is no temporary disturbance or disturbance with less than 5 minutes duration, this indicates that the MAIFI reliability index in section one is very reliable.

\section{F. Reliability Index Analysis}

Analysis of the calculation results shows that there are several factors causing differences in the index of each section as seen in Table 1, i.e., the number of disturbances (blackouts), duration of interruptions (duration of outages), the number of customers served, and length of distribution system channels.

Many disturbances (blackouts) are caused by several factors, for example when short circuit disturbances occur, the electricity will be turned off during the repair time. The duration of disturbance may vary depending on several factors, such as long distance to the location, damaged road, and poor communication network so that the technicians might face some difficulties in getting information about the problem. The number of customers served also greatly influences the reliability index: the more customers served might imply that the more disturbances has occurred, thereby the reliability index increases. In addition, the length of distribution system channel significantly affects the reliability index: the longer the distribution system channel, the greater the possibility of disturbance to occur, compared to a shorter distribution system channel.

Factors affecting the reliability index of the Kumpai feeder are the number and duration of blackouts, the number of customers served, and the length of the distribution system channel. The most dominant factor in Kumpai feeder is disturbances dominated by tree branches, animals, strong winds, kite wires, and others. 


\section{CONClusion}

From the calculation results and analysis of the reliability index, it can be concluded that the highest SAIFI and SAIDI values of Kumpai Feeder are in section 3, i.e., 12,477 times/customer/year and 37,746 hours/ customer/year, respectively. Compared to the standard value of SPLN 68-2: 1986, which is 3.2 times/ customer/year, it can be concluded that the reliability index is fairly poor and unreliable as it has a value greater than the PLN standard.

The CAIDI value of each section is relatively large which indicates that the duration of interruptions occuring in the Kumpai Feeder is still high, so that further improvement is required.

The highest MAIFI value is found in section 2, which is 5,480 times/customer/year, this indicates that the disturbance in section 2 is the highest compared to other sections. Meanwhile, the lowest MAIFI value is found in section 1 , which is 0 times/customer/year, because there are no momentary disturbances or the ones with less than 5 minutes duration. It shows that the MAIFI reliability index in section 1 is very reliable.

From the calculation results, the author concludes that the reliability level of the $20 \mathrm{kV}$ distribution system at PT. PLN (Persero) ULP Siantan at Kumpai Feeder is not reliable. This is because the index values of Kumpai Feeder exceed the standard set by PT. PLN (Persero).

\section{ACKNOWLEDGEMENT}

The author would like to thank the thesis supervisors from the Department of Electrical Engineering, Universitas Tanjungpura for the guidance in writing this article.

\section{REFERENCES}

[1] S. I. Maliky, Alen Tri. Haryudo, "Reliability Analysis of 20 kV Distribution System on a Supporting Feeder at PT. PLN Pasuruan Using RIA Method," Reliability System. Power List. Jar. Distrib. $20 \mathrm{kV}$ There is a Scaffolding Feeder With Method. RIA, vol. 09, no. 01, pp. 835-843, 2020.

[2] I. N. Shofyah, "Analysis of Feeder Disturbance Due to Kites at PT. PLN (Persero) Distribution West Java and Banten Area Garut Rayon Garut Kota," 2014.

[3] H. T. Kurniawan et al., "Using Saidi And Saifi Index At Pt . Pln (Persero) Pontianak Area," 2013.

[4] P. Studi, S. Satu, J. T. Elektro, F. Teknik, and U. Jember, "Digital Repository Universitas Jember," 2010.

[5] P. Zulianti, A. Lomi, and E. Nurcahyo, "Reliability Analysis of Distribution Network Based on Reliability Index Assessment Method: A Case Study.," Int. J. Smart Grid Sustain. Energy Technol., vol. 1, no. 1, pp. 24-27, 2019, doi: 10.36040/ijsgset.v1i1.186.

[6] Diktat of Distribution System Lecture, No Title. pontianak, 2012.

[7] Syakirin, "Evaluation of the reliability of the distribution system of $20 \mathrm{Kv}$ Pt. Pln (Persero) Rayon Ngabang Using the FMEA Method," pp. 1-8, 2018.
[8] L. C. Campbell, Electric Power Transmission System Engineering Analysis and Design, vol. 3, no. 2. 1989.

[9] SPLN Standard 68-2:1986, Part Two. Department of Mining and Energy of The State Electricity General Company, 1986.

[10] State Electricity Company, "Reliability in $20 \mathrm{kV}$ and $6 \mathrm{kV}$ Distribution Systems," pp. 2-7, 1985. 